\title{
Unique nonstructural dysfunction of the omnicarbon valve: case report
}

\author{
Soki Kurumisawa, Yuichiro Kaminishi, Arata Muraoka and Yoshio Misawa*
}

\begin{abstract}
Background: Pannus formation may disturb the leaflet movement of the prosthetic valve.

Case presentation: A 61-year-old woman presented with exertional dyspnea. She had undergone mitral valve replacement with a bioprosthetic valve 31 years ago, which was replaced with a tilting disc valve 22 years ago. The present laboratory findings revealed hemolytic anemia. Echocardiography showed an increased mean pressure gradient through the mitral valve and moderate to severe regurgitation around the minor orifice of the tilting disc valve. She therefore underwent a third operation. Pannus formation was found on the prosthetic valve ring, but it did not obliterate the prosthetic valve orifice. After removing the valve, the posterior wall of the left ventricle was seen to be associated with thickened endocardium. A bileaflet valve was implanted. Postoperative echocardiography showed that the implanted valve functioned well.
\end{abstract}

Conclusions: Nonstructural dysfunction of the mechanical heart valve might occur long after operation. These changes are particularly observed with a tilting disc valve.

Keywords: Mitral valve replacement, Omnicarbon valve, Pannus formation

\section{Background}

Nonstructural dysfunction of the mechanical heart valve may be caused by paravalvular leak, prosthetic valve endocarditis, and/or pannus formation. The latter may disturb the leaflet movement of the prosthesis and may grow beyond the suture ring. We describe a patient who was diagnosed with mitral valve stenosis and regurgitation 22 years after her implanted bioprosthetic valve was replaced with an Omnicarbon valve (Medical Incorporated, Minneapolis, MN, USA).

\section{Case presentation}

A 61-year-old woman presented with a 10-month history of exertional dyspnea. She had had rheumatic heart valve disease and had undergone mitral valve replacement with a Carpentier Edwards valve (Edwards Lifesciences, Irvine, CA, USA) without preservation of the posterior leaflet of the mitral valve 31 years ago. Because of primary tissue failure of this implanted valve, she underwent valve replacement for with an Omnicarbon valve 22 years ago. During this second replacement, the

\footnotetext{
* Correspondence: tcvmisa@jichi.ac.jp

Division of Cardiovascular Surgery, Jichi Medical University, 3311-1 Yakushiji, Shimotuske, Tochigi 329-0498, Japan
}

bioprosthetic valve was removed, and the Omnicarbon valve was implanted in an intra-annular position, with the major orifice orientated posteriorly. Our standard method then was a U-suture technique using 2-0 sutures with pledgets. Controlled Anticoagulation therapy combined with paramidine was applied postoperatively.

At the present admission, laboratory findings revealed a white blood cell count of $2100 / \mu \mathrm{l}$, hemoglobin of $9.7 \mathrm{~g} / \mathrm{dl}$, and slight elevations in the serum levels of aspartate aminotransferase $(54 \mathrm{mU} / \mathrm{ml})$, lactate dehydrogenase $(1277 \mathrm{mU} / \mathrm{ml})$, and total bilirubin $(2.65 \mathrm{mg} / \mathrm{dl})$. Brain natriuretic peptide was also elevated $(100.8 \mathrm{pg} / \mathrm{ml})$.

Chest radiography showed a high cardiothoracic ratio of $86 \%$ with right pleural effusion. Electrocardiography revealed atrial fibrillation with an extremely low $f$ wave. Trans-thoracic echocardiography showed that the peak flow velocity of the Omnicarbon valve was $2.7 \mathrm{~m} / \mathrm{s}$, the mean pressure gradient between the left atrium and ventricle was $15 \mathrm{mmHg}$, and moderate-to-severe mitral valve regurgitation around from the minor orifice of the Omnicarbon valve (Fig. 1) with an enlarged left atrium $(80 \mathrm{~mm})$. The left ventricular ejection fraction was $60 \%$ with left ventricular end-diastolic/end-systolic dimensions of $47 / 34 \mathrm{~mm}$. Preoperative computed 


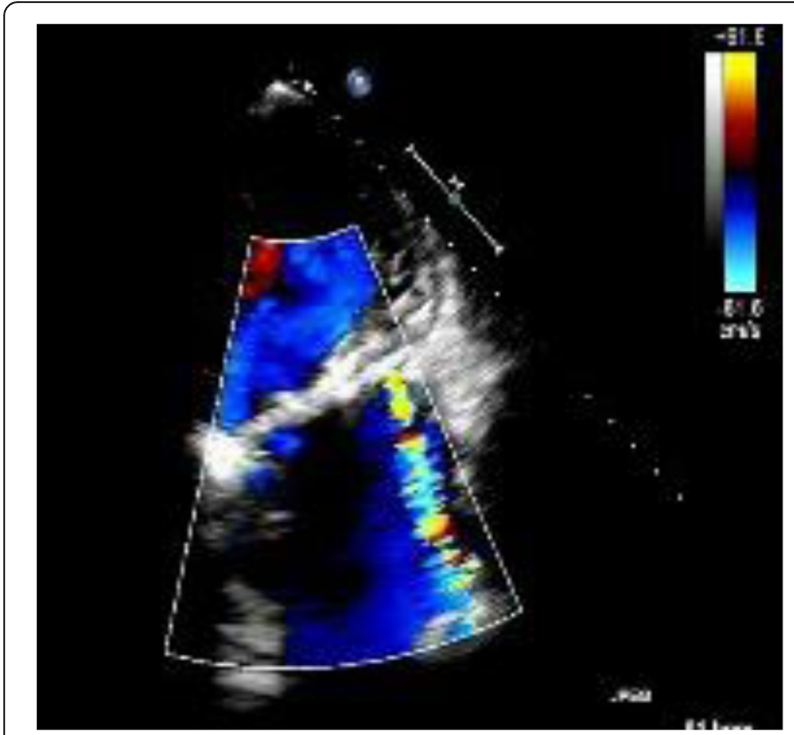

Fig. 1 Preoperative echocardiographic findings of a long axis view. Mitral valve regurgitation is apparent around the minor orifice of the implanted valve. The left atrium is enlarged

tomography also showed the enlarged left atrium and right pleural effusion. Left ventriculography disclosed that mitral valve regurgitation from the minor orifice of the Omnicarbon valve and the enlarged left atrium (Fig. 2, Additional file 1).

The patient obviously required another operation. Standard cardiopulmonary bypass was established. Under cardiac arrest, right-sided left atriotomy allowed visualization of the implanted valve. Pannus formation

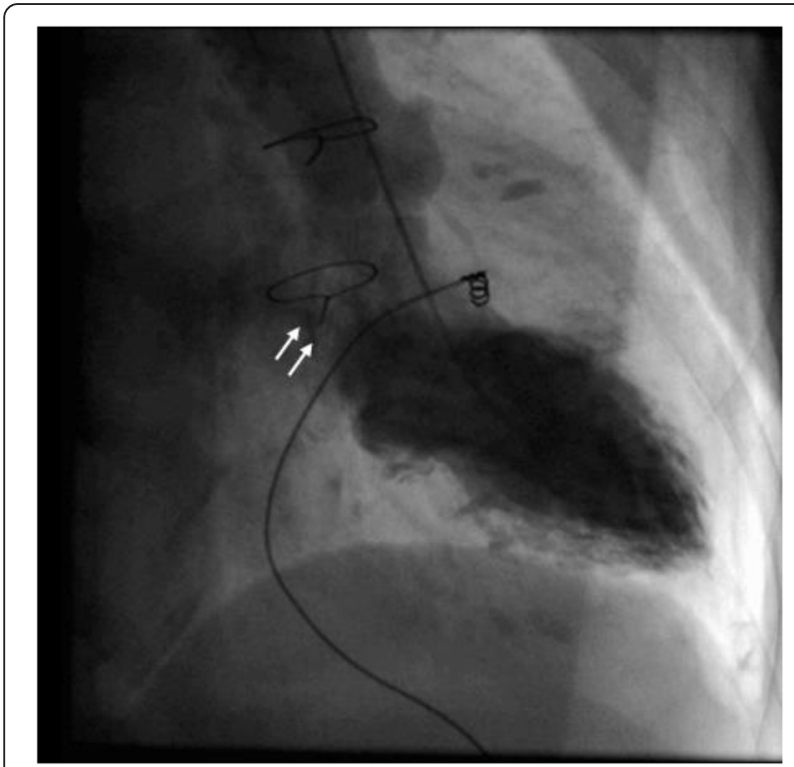

Fig. 2 Left ventriculographic findings. Mitral valve regurgitation from the minor orifice of the Omnicarbon valve is observed (white arrows)

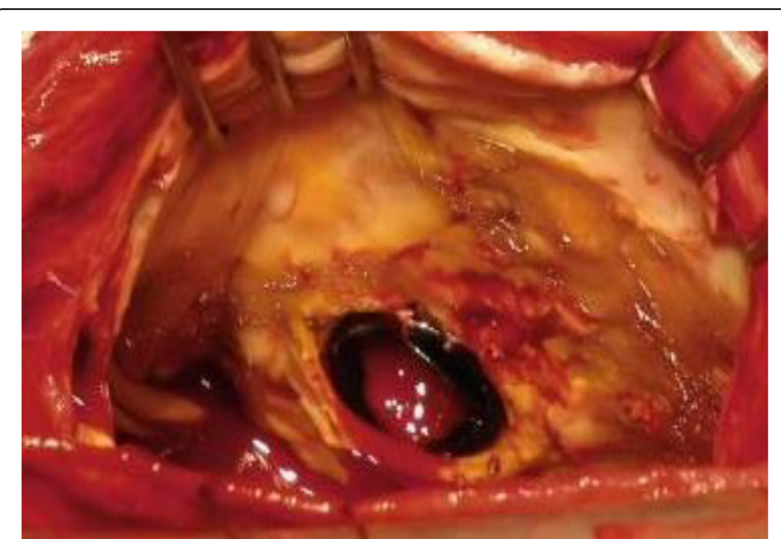

Fig. 3 Operative findings of the implanted valve. The suture ring of the implanted prosthesis is covered with pannus, although it is not obliterating the valve orifice

was apparent on the prosthetic valve ring (Fig. 3), but it did not obliterate the prosthetic valve orifice on either the atrial or ventricular aspects. After removing the valve, the posterior wall of the left ventricle was seen to be associated with thickened endocardium. A $27 \mathrm{~mm}$ Bicarbon bileaflet valve (Sorin Biomedica, Saluggia, Italy) was implanted in an intra-annular position. Plication of the left atrium was undertaken along the incisional line and between the mitral posterior annulus and bilateral pulmonary vein orifices. Weaning from the cardiopulmonary bypass was easy, and her postoperative course was uneventful.

Postoperative echocardiography showed a mean pressure gradient of $4.3 \mathrm{mmHg}$ between the left atrium and ventricle with no mitral valve regurgitation. The left atrium was slightly reduced to $71 \mathrm{~mm}$, and the left ventricular end-diastolic/end-systolic dimension was 50/ $32 \mathrm{~mm}$ with an ejection fraction of $65 \%$. She was doing well after one and a half years after the operation.

\section{Discussion}

Edmunds and coworkers designed the guidelines for reporting outcomes after prosthetic valve replacement, stating that valve-related complications include thromboembolisms, bleeding complications, prosthetic valve endocarditis, and structural and nonstructural prosthetic valve dysfunctions [1]. Nonstructural valve dysfunction may include paravalvular leak with no apparent endocarditis, cusp entrapment by pannus, and others.

Pannus could prevent a prosthetic valve leaflet from functioning well. This complication is found mainly at long-term follow-up evaluations. We earlier reported four patients who required reoperation because of pannus formation [2,3]. One of the patients who had pannus at the aortic position underwent reoperation at 97 months. In two others, pannus was at the mitral position and in another it was at both the aortic and 

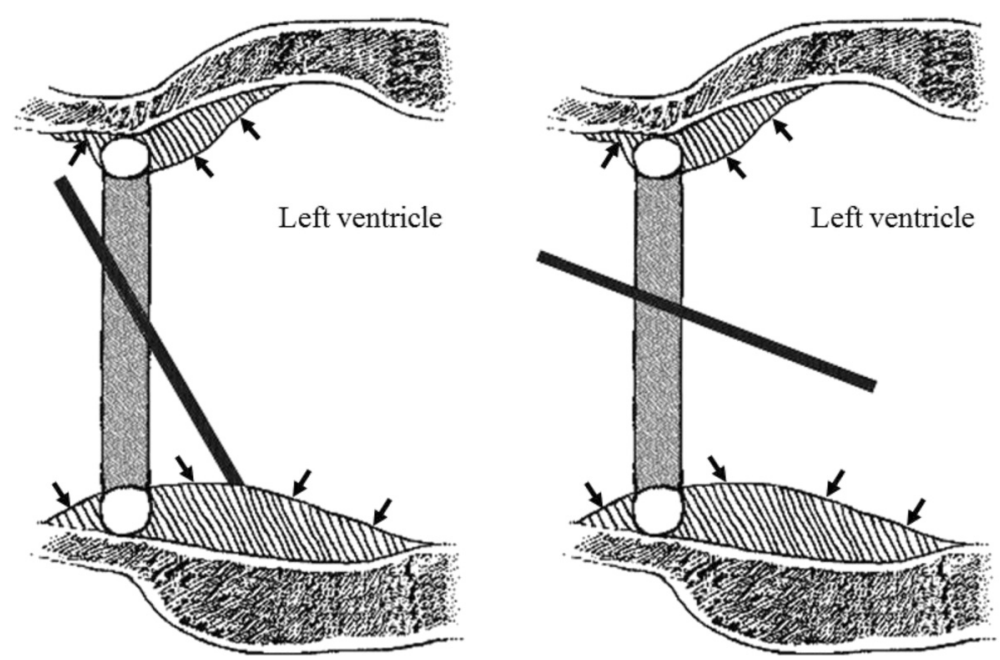

Fig. 4 Mechanisms of valve dysfunction of our case. The thickened left ventricular posterior wall associated with pannus growth (black arrows) might lead to a stenosis, and it could prevent the disc from closing completely in the case of a tilting disc valve

mitral positions. These three patients had been diagnosed 20-39 years after their initial operations.

$\mathrm{Oh}$ and coworkers reported that the mean interval from the previous operation to the diagnosis of pannus at the aortic position that was causing dysfunction was $16.7 \pm 4.3$ years [4]. The authors noted that the most common etiology for the previous surgery was valve disease associated with prior rheumatic fever. Ellensen and colleagues also reported a series of 27 cases. They showed that women and younger patients had a higher risk of pannus formation at the aortic position [5]. Doshi and coworkers reported a case of intermittent opening of a mitral tilting disc prosthesis 23 years after implantation [6]. They showed a circumferential pannus on the ventricular aspect on the free margin of the disc.

Pannus overgrowth was recognized in our patient, but it was limited to the suture ring. Preoperative findings indicated prosthetic valve dysfunction with mitral stenosis and regurgitation. Based on the operative findings, we surmised that the posterior wall of the left ventricle had been thickened by a blood flow through the major orifice of the tilting disc. Tilting disc valves do not have laminar, unlike bileaflet prostheses [7]. The thickened left ventricular posterior wall associated with pannus growth might lead to a stenosis, which could prevent the disc from closing completely in the case of a tilting disc valve (Fig. 4). It would be less likely to occur in a bileaflet valve.

In valve disease associated with prior rheumatic fever, the endocardium generally has inflammatory changes, including thickening. Repeated surgeries may also contribute to endocardial thickening.

Pannus that exceeds the suture ring can be resected through the prosthetic valve [8], but subannular pannus or fibrous tissue is not easy to remove. Therefore, valve replacement is an adequate treatment strategy. A bileaflet prosthesis produces parallel laminar flows, and their low profile characteristics can avoid restricted leaflet functioning at the anti-anatomical position of the mitral valve in case of subannular hypertrophic changes.

\section{Conclusions}

Subannular pannus formation and fibrous hypertrophic changes of the posterior portion of the left ventricle can cause mechanical heart valve dysfunction. These changes are particularly observed with a tilting disc valve.

\section{Consent}

Written informed consent was obtained from the patient for publication of this Case report and any accompanying images.

\section{Additional file}

Additional file 1: Left ventriculography. Mitral valve regurgitation from the minor orifice of the Omnicarbon valve is observed. (MOV $4181 \mathrm{~kb}$ )

\section{Competing interests}

Misawa Y serves as a consultant to Terumo Co. and Edwards Lifescience Co. The other authors have no competing interests.

\section{Authors' contribution}

SK participated in the design of the study. YK and AM participated in its design and coordination. YM helped draft the manuscript. All authors read and approved the final manuscript.

\section{Acknowledgement}

Ms. Ueno E drew an illustration. Mr. Yajima S and Mr. Harada Y cooperated to make image materials. 


\section{Funding}

This study received no specific grant from any funding agency in the public, commercial, or not-for-profit sectors.

Received: 12 August 2015 Accepted: 23 March 2016

Published online: 29 March 2016

\section{References}

1. Edmunds LH, Clark RE, Cohn LH, Grunkemeier GL, Miller DC, Weisel RD. Guideline for reporting morbidity and mortality after cardiac valvular operations. Ann Thorac Surg. 1996;62:932-5.

2. Misawa Y, Saito T, Konishi H, Oki S, Kaminishi Y, Aizawa K, Takahashi H, Kamisawa O, Kato M, Fuse K. When and how does mechanical prosthetic heart valve dysfunction appear? Jpn J Thorac Cardiovasc Surg. 2003;51:355-60.

3. Misawa S, Aizawa K, Kaminishi Y, Muraoka A, Misawa Y. Starr-Edwards valves at the aortic and mitral positions implanted for 39 years. Gen Thorac Cardiovasc Surg. 2011;59:433-5.

4. Oh SJ, Park S, Kim JS, Kim KH, Kim KB, Ahn H. Reoperation for non-structural valvular dysfunction caused by pannus ingrowth in aortic valve prosthesis. J Heart Valve Dis. 2013:22:591-8.

5. Ellensen VS, Andersen KS, Vitale N, Davidsen ES, Segadal L, Haaverstad R. Acute obstruction by pannus in patients with aortic medtronic-hall valves: 30 years of experience. Ann Thorac Surg. 2013;96:2123-8.

6. Doshi SN, Sharma SK, Been M. Intermittent opening of a mitral valve tilting disc prosthesis 23 years after implantation caused by circumferential pannus. Heart. 2003:89:1049.

7. Misawa Y, Fuse K, Kamisawa O, Kawahito K, Konishi H. Echocardiographic characteristics of transprosthetic blood peak velocity in the Sorin Bileaflet prosthetic heart valve. J Artif Organs. 1999;2:74-7.

8. Misawa Y, Fuse K, Kato M. Pannus resection through the tilting disc prosthesis: successful treatment preserving the proathesis. Artif Organs. 1997;21:1301-2.

\section{Submit your next manuscript to BioMed Central and we will help you at every step:}

- We accept pre-submission inquiries

- Our selector tool helps you to find the most relevant journal

- We provide round the clock customer support

- Convenient online submission

- Thorough peer review

- Inclusion in PubMed and all major indexing services

- Maximum visibility for your research

Submit your manuscript at www.biomedcentral.com/submit 